EVIDENCE BASED PUBLIC HEALTH POLICY AND PRACTICE

\title{
Infections, medication use, and the prevalence of symptoms of asthma, rhinitis, and eczema in childhood
}

\author{
Catherine Cohet, Soo Cheng, Claire MacDonald, Michael Baker, Sunia Foliaki, Nyk Huntington, \\ Jeroen Douwes, Neil Pearce
}

J Epidemiol Community Health 2004;58:852-857. doi: 10.1136/jech.2003.019182

See end of article for authors' affiliations

Correspondence to:

Professor N Pearce, Centre for Public Health Research, Research School of Public Health, Massey University Wellington Campus, Private Box 756, Wellington, New Zealand; n.e.pearce@massey.ac.nz

Accepted for publication 24 February 2004
Background: The "hygiene hypothesis" postulates that infections during infancy may protect against asthma and atopy. There is also some evidence that antibiotic and/or paracetamol use may increase the risk of asthma.

Methods: The study measured the association between infections, and medication use early in life and the risk of asthma at age 6-7 years. It involved 1584 children who had been notified to public health services with serious infections at age 0-4 years, and 2539 children sampled from the general population. For both groups, postal questionnaires were completed by parents.

Results: There was little difference in the prevalence of current wheezing between the childhood infections group (prevalence $=23.5 \%$ ) and the general population group (prevalence $=24.3 \%$ ). There was also little difference whether the major site of infection was gastrointestinal (prevalence $=24.1 \%$ ), invasive (prevalence $=24.6 \%$ ) or respiratory (prevalence $=21.1 \%$ ). However, in both groups, there were associations with antibiotic $(O R=1.78,95 \% \mathrm{Cl} 1.49$ to 2.14 ) or paracetamol $(\mathrm{OR}=1.38,95 \% \mathrm{Cl} 1.04$ to 1.83) use in the first year of life or recent paracetamol use $(\mathrm{OR}=2.10,95 \% \mathrm{Cl} 1.78$ to 2.49$)$ and current wheezing. There was a weak protective effect of childhood infections in children who had not used antibiotics in the first year of life (OR $=0.78,95 \% \mathrm{Cl} 0.55$ to 1.10$)$.

Conclusions: These findings are consistent with other evidence that antibiotic use early in life may increase the risk of asthma. They are also consistent with some preliminary evidence associating paracetamol use with an increased risk of asthma. Any protective effect of notifiable childhood infections was weak.
$\mathrm{T}$ he "hygiene hypothesis" postulates that infections during infancy may protect against asthma and atopy by down-regulating production of IgE. ${ }^{1-6}$ This hypothesis was first suggested by the striking associations between small family size and hay fever, atopy, and in some instances asthma. $^{7}$ Subsequent studies have observed that infections early in life may protect against the development of asthma, but the evidence is far from consistent. ${ }^{8-27}$ Furthermore, the effect of infections may differ with the type (viral, parasitic, or bacterial) and location (respiratory versus gastrointestinal) of infection. ${ }^{27}$ A related issue is that antibiotic use may increase the risk of asthma by affecting immunological responses to bacteria through preventing infections or causing major disruptions to the gut bacterial flora. ${ }^{28}{ }^{29}$ However, the evidence has also been conflicting. ${ }^{30-36}$ Paracetamol use has also been suggested to increase the risk of asthma. ${ }^{37-40}$

We have therefore investigated the association between infections at age 0-4 years, medication use (antibiotics and paracetamol) early in life, and the subsequent risk of childhood asthma at age 6-7 years. This study was based on data from the New Zealand National Notifiable Diseases Database (EpiSurv), which includes confirmed cases of serious childhood infections identified through a national compulsory notification system. We compared the findings in this "childhood infections group" with the data from phase III of the international study of asthma and allergies in childhood (ISAAC), ${ }^{41}$ which was conducted in Wellington in the same age group during the same period.

\section{METHODS}

\section{Study populations}

The "childhood infections group" consisted of children with notifiable infectious diseases reported to public health services and recorded on the EpiSurv database. ${ }^{42}$ Health professionals are required to inform their local medical officer of health of any notifiable disease that they suspect or diagnose. Notification data are recorded in a computerised database (EpiSurv) installed in each public health service. The database included 4838 infections in children aged 0-4 years who were born during 1994-1995; we excluded 19 children for whom the infection was fatal, 8 who were found to have subsequently died from another cause, 632 with incomplete names or addresses, and 45 duplications (different episodes of infections for the same child), leaving 4134 children. The database included the names and addresses of the parents at the time of the notification to the EpiSurv database. We only included in the survey children who were still living at the same address as they were at the time of the notification; if they were confirmed to have moved, they were excluded ( 1372 children); this left 2762 children eligible for inclusion. The survey was conducted in the first half of 2002.

The "general population group" comprised the participants in the Wellington survey for 6-7 year olds that was conducted in Wellington during April-October 2002. Thus, the general population group (which covered the Wellington region) involved a smaller catchment area than the childhood infections group (which was national). We approached all 153 primary schools in the greater Wellington region (Wellington, the Hutt Valley, and Porirua), of which 85 agreed to participate; these included 5375 children in the 6-7 year age group.

\section{Data collection}

For both groups, the parents were mailed the ISAAC phase III questionnaire on asthma symptoms and environmental exposures in children aged 6-7 years. ${ }^{41}$ The basic questions on symptoms of asthma, rhinitis, and eczema are the same as for the ISAAC phase I survey, ${ }^{43}$ but the phase III 
questionnaire includes additional questions on environmental exposures. For the childhood infections group, the parents received three mailings, and then if there was still no response the parents were called and asked to answer the questionnaire over the telephone. Most children in the general population group only received one mailing because the schools were not willing to permit further mailings to be sent through their offices or to provide the contact details of parents.

\section{Data analysis}

The analyses involved the key questions on the prevalence of symptoms of asthma, rhinitis, and eczema from the ISAAC questionnaire. ${ }^{4143}{ }^{44}$ For the symptom questions, we followed the standard practice for ISAAC questionnaires and divided the respondents into those with a positive response and those with either a negative or missing response ${ }^{44}$ (whereas for the questions on environmental exposures, missing values were treated as "missing" in the analysis). The key asthma questions used were those on "wheeze in the past 12 months" ("current wheezing") and "asthma ever"; the key hay fever questions were those on "problems with sneezing, or a runny, or a blocked nose when not having a cold or the flu in the past 12 months" (when these problems were "accompanied by itchy-watery eyes") ("allergic rhinoconjunctivitis") and "hay fever ever", ${ }^{45}$ and the key eczema question used was "eczema ever". ${ }^{46}$

We examined the overall prevalences in the two surveys, and also conducted sub-analyses of the childhood infections group. For the analysis by major site of infection, the first categories used were: (a) gastrointestinal infections (1216) including campylobacteriosis (640), cryptosporidiosis (98), food poisoning (3), giardiasis (237), salmonellosis (175), shigellosis (9), verotoxin producing Escherichia coli (VTEC) infection (4) and yersiniosis (43); (b) invasive infections (118) such as septicaemia and meningitis caused by Haemophilus influenza type B (Hib) (2) and meningococcal disease (116); (c) respiratory tract infections (128) including pertussis (106), new cases of tuberculosis disease (9) and tuberculosis infection in chemotherapy treated children (13); and (d) childhood viral infections (122) including measles (88), mumps (8) and rubella (26). The second subgroup analysis was conducted by pathogen type: (a) bacterial infections (1119) including campylobacteriosis (640), Hib infection (2), meningococcal disease (116), pertussis (106), salmonellosis (175), shigellosis (9), tuberculosis (22), VTEC infection (4) and yersiniosis (43); (b) protozoan infections (335) including cryptosporidiosis (98) and giardiasis (237); and (c) childhood viral infections (the same as the fourth category in the first analysis).

The data were analysed using standard methods for asthma prevalence studies. ${ }^{47}$ The associations of specific exposures with symptom prevalence were estimated using prevalence odds ratios, with adjustment for confounding using the Mantel-Haenszel method ${ }^{48}$ and logistic regression. ${ }^{49}$ The data were analysed using Stata (Stata Statistical Software, Release 7.0; Stata Corporation, College Station, TX, USA, 2001). After conducting the separate analyses of the general population group and the childhood infections group, we found that the key findings were very similar within

Table 1 Prevalence of symptoms of asthma, rhinitis, and eczema in children aged 6-7 years in the general population survey and the infections survey, by major site of infection and pathogen type

\begin{tabular}{|c|c|c|c|c|c|c|c|c|}
\hline & \multirow{2}{*}{$\begin{array}{l}\begin{array}{l}\text { General } \\
\text { population* }\end{array} \\
\begin{array}{l}N=2539 \\
\%(n)\end{array}\end{array}$} & \multirow{2}{*}{$\begin{array}{l}\begin{array}{l}\text { Infections } \\
\text { groupt }\end{array} \\
\begin{array}{l}\mathrm{N}=1584 \\
\%(\mathrm{n})\end{array}\end{array}$} & \multicolumn{3}{|c|}{ Major site of infection } & \multicolumn{2}{|c|}{ Pathogen type } & \multirow{2}{*}{$\begin{array}{l}\text { Childhood viral } \\
\begin{array}{l}N=122 \\
\%(n)\end{array}\end{array}$} \\
\hline & & & $\begin{array}{l}\text { Gastrointestinal } \\
N=1216 \\
\% \text { (n) }\end{array}$ & $\begin{array}{l}\text { Invasive } \\
N=118 \\
\%(n)\end{array}$ & $\begin{array}{l}\text { Respiratory } \\
\mathrm{N}=128 \\
\%(n)\end{array}$ & $\begin{array}{l}\text { Bacteria } \\
N=1119 \\
\%(n)\end{array}$ & $\begin{array}{l}\text { Protozoan } \\
\mathrm{N}=335 \\
\%(\mathrm{n})\end{array}$ & \\
\hline \multicolumn{9}{|l|}{ Asthma symptoms } \\
\hline Wheezing ever & $44.5(1130)$ & $46.1(730)$ & $46.4(564)$ & $46.6(55)$ & $49.2(63)$ & $46.7(522)$ & $46.3(155)$ & $39.3(48)$ \\
\hline Wheezing in the past 12 months & $24.3(618)$ & 23.5 (372) & $24.1(293)$ & $24.6(29)$ & $21.1(27)$ & $24.1(270)$ & $23.3(78)$ & $18.9(23)$ \\
\hline $\begin{array}{l}\geqslant 1 \text { wheezing attack in the past } \\
12 \text { months }\end{array}$ & $24.0(610)$ & 23.5 (372) & $24.0(292)$ & $24.6(29)$ & $24.2(28)$ & $24.0(268)$ & $23.9(80)$ & $18.9(23)$ \\
\hline $\begin{array}{l}\text { Night waking in the past } \\
12 \text { months }\end{array}$ & $14.8(376)$ & $14.6(231)$ & $15.1(183)$ & $16.9(20)$ & $14.1(18)$ & $15.6(174)$ & $13.7(46)$ & $8.2(10)$ \\
\hline $\begin{array}{l}\text { Severe wheeze in the past } \\
12 \text { months }\end{array}$ & 4.1 (103) & $4.2(67)$ & $4.4(53)$ & $5.9(7)$ & $3.1(4)$ & $4.6(51)$ & $3.9(13)$ & $2.5(3)$ \\
\hline Asthma ever & $32.8(833)$ & $31.9(506)$ & $32.2(391)$ & $29.7(35)$ & $30.5(39)$ & $30.9(346)$ & $34.6(116)$ & $33.6(41)$ \\
\hline Exercise wheeze & 16.9 (428) & $17.8(282)$ & $18.3(223)$ & $15.3(18)$ & $16.4(21)$ & 17.3 (194) & $19.7(66)$ & $16.4(20)$ \\
\hline $\begin{array}{l}\text { Night cough in the past } \\
12 \text { months }\end{array}$ & 30.8 (782) & 31.0 (490) & 30.8 (375) & 31.4 (37) & 30.5 (39) & $30.4(340)$ & 31.9 (107) & 32.0 (39) \\
\hline \multicolumn{9}{|l|}{ Rhinitis symptoms } \\
\hline Nose symptoms ever & $29.5(748)$ & $31.3(495)$ & $31.7(385)$ & $34.8(41)$ & $29.7(38)$ & $32.0(358)$ & $30.5(102)$ & $25.4(31)$ \\
\hline $\begin{array}{l}\text { Nose symptoms in the past } \\
12 \text { months }\end{array}$ & $26.3(669)$ & $28.2(446)$ & 28.7 (349) & 29.7 (35) & 25.8 (33) & 29.0 (325) & $26.6(89)$ & $23.8(29)$ \\
\hline $\begin{array}{l}\text { Eyes affected in the past } \\
12 \text { months }\end{array}$ & $12.0(304)$ & $14.0(221)$ & $14.2(173)$ & $17.0(20)$ & 14.1 (18) & $15.1(169)$ & $12.2(41)$ & $8.2(10)$ \\
\hline $\begin{array}{l}\text { Activities limited in the past } \\
12 \text { months }\end{array}$ & $16.4(417)$ & $18.4(292)$ & 19.5 (237) & $22.0(26)$ & 11.7 (15) & $19.4(217)$ & $17.3(58)$ & $11.5(14)$ \\
\hline $\begin{array}{l}\text { Hay fever ever } \\
\text { Eczema symptoms }\end{array}$ & $17.3(440)$ & $18.2(288)$ & $18.3(223)$ & $21.2(25)$ & $17.2(22)$ & $19.0(213)$ & $15.8(53)$ & $14.8(18)$ \\
\hline Rash ever & $27.0(686)$ & $26.0(412)$ & $25.8(314)$ & $28.8(34)$ & $22.7(29)$ & $26.6(298)$ & $22.1(74)$ & $28.7(35)$ \\
\hline Rash in the past 2 months & $23.0(583)$ & $22.7(360)$ & $22.7(276)$ & $25.4(30)$ & $19.5(25)$ & $23.4(262)$ & $19.1(64)$ & $23.8(29)$ \\
\hline Flexural areas ever & $21.0(533)$ & $19.6(310)$ & $19.7(238)$ & $18.6(22)$ & $18.8(24)$ & $19.9(223)$ & $17.3(58)$ & $21.3(26)$ \\
\hline $\begin{array}{l}\text { Rash cleared in the past } \\
12 \text { months }\end{array}$ & $16.6(421)$ & $16.5(262)$ & $16.9(205)$ & $17.0(20)$ & $10.9(14)$ & $17.0(190)$ & $13.1(44)$ & $18.9(23)$ \\
\hline $\begin{array}{l}\text { Night waking in the past } \\
12 \text { months }\end{array}$ & $10.2(258)$ & 9.9 (157) & $10.1(123)$ & $15.3(18)$ & $8.6(11)$ & $11.1(124)$ & $8.1(27)$ & $4.1(5)$ \\
\hline Eczema ever & 39.9 (1013) & $37.9(601)$ & $38.2(464)$ & $34.8(41)$ & $34.4(44)$ & $37.3(417)$ & 38.5 (129) & $42.6(52)$ \\
\hline
\end{tabular}




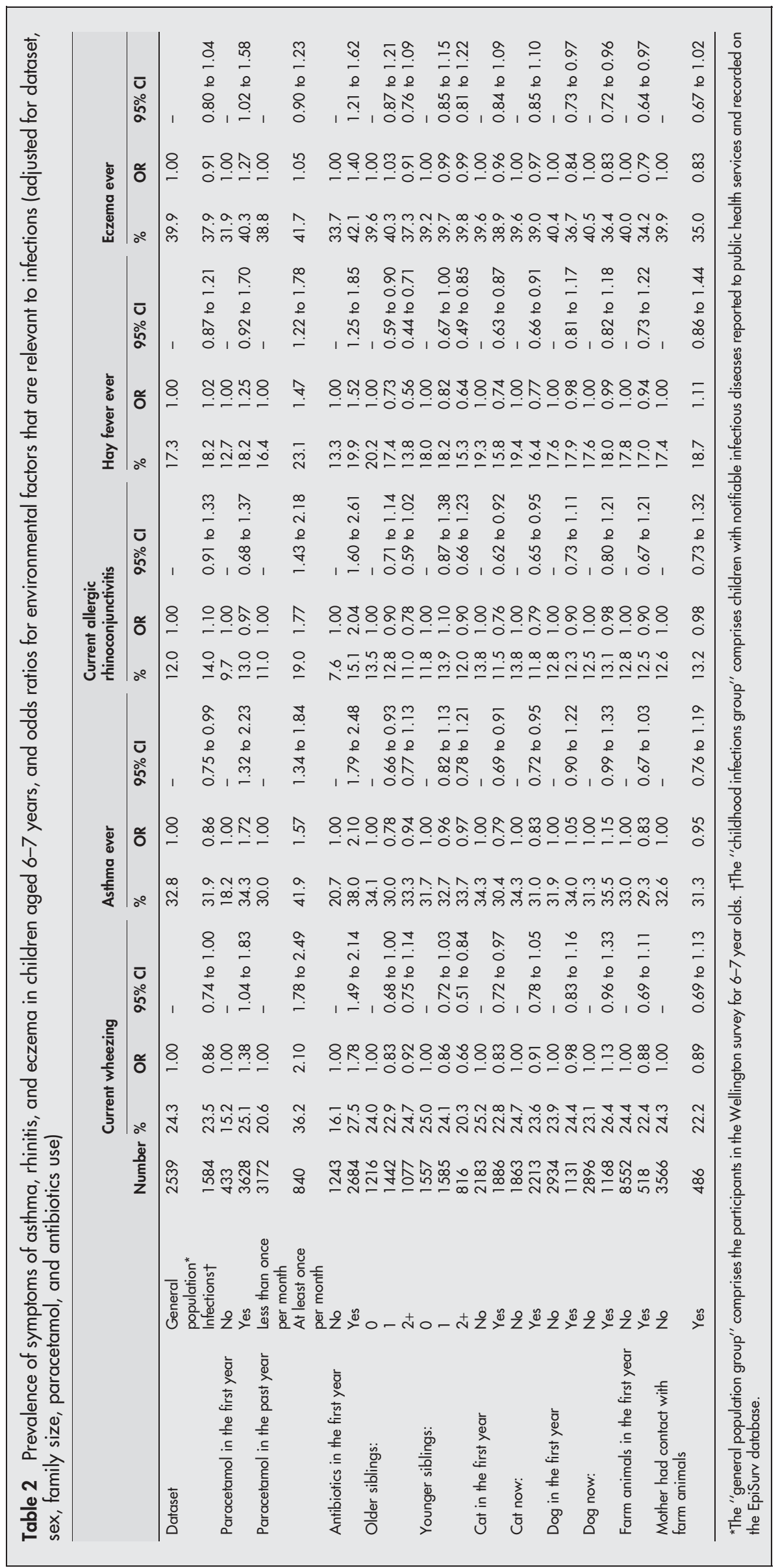




\section{Key points}

- Antibiotic use early in life may increase the subsequent risk of asthma.

- The use of paracetamol early in life, or recent paracetamol use, may also increase the risk of asthma

- There is at most a weak protective effect of notifiable childhood infections on the subsequent risk of developing asthma.

the two groups so we combined the two groups and adjusted for "dataset" in the final analyses.

\section{Ethics}

The study was approved by the Massey University Human Ethics Committee (protocol 00/154) and conformed to the principles embodied in the Declaration of Helsinki.

\section{RESULTS}

The response rates were low, but similar in the two surveys: $1584(57 \%)$ of parents responded to the survey of the childhood infections group; and 2539 (47\%) of parents responded to the survey of the general population group.

\section{Childhood infections}

There were no significant differences in prevalences of reported symptoms of asthma, rhinitis, and eczema between the two groups (for example, the prevalence of current wheezing was $23.5 \%$ in the childhood infections group and $24.3 \%$ in the general population group), or between the various subgroups of the childhood infections group (table 1). Also, there was little difference according to the age at which infection occurred (not shown in table): the prevalences of current wheezing were $23.1 \%$ in those with infections in the first year of life $(n=242), 20.5 \%$ in those with infections at age $1-2$ years $(n=536)$, and $25.6 \%$ in those with infections at age $3-4$ years $(n=806)$.

Table 2 shows the adjusted prevalence odds ratios for infections and other relevant exposures. For current wheezing there was a weak protective effect $(\mathrm{OR}=0.86,95 \% \mathrm{CI}$ 0.74 to 1.00 ) of serious childhood infections (defined as being in the childhood infections dataset rather than in the general population dataset). When we restricted the analysis to children who had not been reported as using antibiotics in the first year of life (not shown in table) there was a slightly stronger (non-statistically significant) protective effect of infections $(\mathrm{OR}=0.78,95 \%$ CI 0.55 to 1.10$)$, whereas there was less evidence of a protective effect in children who had been reported as using antibiotics early in life $(\mathrm{OR}=0.95$, $95 \%$ CI 0.54 to 1.65 ).

\section{Policy implications}

- These findings should be regarded as provisional and preliminary and there are therefore no immediate policy implications.

- However, if these findings are confirmed in further research then they would indicate the need for greater caution in the use of both antibiotics and paracetamol early in life.

\section{Paracetamol and antibiotics}

Table 2 also shows the adjusted prevalence odds ratios for paracetamol and antibiotic use. The use of paracetamol during the first year of life was weakly associated with current wheezing (OR $=1.38,95 \%$ CI 1.04 to 1.83 ), asthma $(\mathrm{OR}=1.72,95 \% \mathrm{CI} 1.32$ to 2.23$)$, hay fever $(\mathrm{OR}=1.25,95 \%$ CI 0.92 to 1.70 ), and eczema 1.27 (95\% CI 1.02 to 1.58 ), but not rhinoconjunctivitis ( $\mathrm{OR}=0.97,95 \%$ CI 0.68 to 1.37). Recent use of paracetamol at least once per month was associated with current wheezing $(\mathrm{OR}=2.10,95 \% \mathrm{CI} 1.78$ to $2.49)$, asthma (OR $=1.57,95 \%$ CI 1.34 to 1.84$)$, rhinoconjunctivitis $(\mathrm{OR}=1.77,95 \%$ CI 1.43 to 2.18$)$, and hay fever $(\mathrm{OR}=1.47,95 \% \mathrm{CI} 1.22$ to 1.78$)$ but not eczema $(\mathrm{OR}=1.05$, $95 \%$ CI 0.90 to 1.23). Stronger associations were observed with the use of antibiotics in the first year of life with current wheezing $(\mathrm{OR}=1.78,95 \% \mathrm{CI} 1.49$ to 2.14$)$, asthma $(\mathrm{OR}=2.10,95 \%$ CI 1.79 to 2.48$)$, rhinoconjunctivitis $(\mathrm{OR}=2.04,95 \% \mathrm{CI} 1.60$ to 2.61$)$, hay fever $(\mathrm{OR}=1.52,95 \%$ CI 1.25 to 1.85$)$, and eczema $(\mathrm{OR}=1.40,95 \%$ CI 1.21 to 1.62). We found similar odds ratios for antibiotics when we restricted the analysis to the childhood infections group or to the general population group (not shown in tables).

We conducted analyses for paracetamol and/or antibiotic use stratified by type of infection but these generally yielded findings similar to the overall analyses (results not shown in tables). However, the risk of current wheezing in association with the use of paracetamol in the first year of life was higher in those with salmonellosis ( OR $=9.21$ 95\% CI 1.15 to 73.84$)$.

\section{Factors related to infections}

With regard to other factors related to infections (table 2), there was a reduced prevalence of reported hay fever in children with two or more older siblings (OR $=0.56,95 \%$ CI 0.44 to 0.71$)$, and in children with one older sibling ( $\mathrm{OR}=0.73,95 \%$ CI 0.59 to 0.90$)$, when compared with children with no older siblings. The associations for older siblings were weaker for the other symptoms and outcomes considered (table 2). On the other hand, for younger siblings, the strongest associations were for current wheezing ( $\mathrm{OR}=0.66,95 \%$ CI 0.51 to 0.84 for two or more compared with no younger siblings).

Having a cat in the home during the first year of life was protective against current wheezing $(\mathrm{OR}=0.83,95 \% \mathrm{CI} 0.72$ to 0.97 ), asthma (OR $=0.79,95 \%$ CI 0.69 to 0.91 ), allergic rhinoconjunctivitis ( $\mathrm{OR}=0.76$, 95\% CI 0.62 to 0.92 ), hay fever $(\mathrm{OR}=0.74,95 \%$ CI 0.63 to 0.87$)$ but not eczema $(\mathrm{OR}=0.96,95 \%$ CI 0.84 to 1.09$)$; similar results were found for current cat ownership. No effect of contact with dogs was observed, although currently living with a dog was negatively associated with eczema ( $\mathrm{OR}=0.83,95 \%$ CI 0.72 to 0.96 ). Contact with farm animals in the first 12 months of life was weakly (non-significantly) protective against subsequent asthma, as was the mother's exposure to farm animals during pregnancy.

\section{DISCUSSION}

The primary reason for conducting this study was to investigate the potential protective effect of notifiable childhood infections for the subsequent development of asthma. We found at most a weak protective effect, although it should be emphasised that the study was confined to infections that were notified to public health authorities, and the findings cannot be extrapolated to childhood infections in general. On the other hand, we found an increased risk of asthma from the use of antibiotics and/or paracetamol in the first year of life, and also for recent paracetamol use.

Both surveys had low response rates. However, it is unlikely that these will have seriously biased our findings 
because: (a) the response rates were similar in the two surveys; (b) the prevalence estimates obtained in the general population group were very similar to those obtained in the same population in the ISAAC phase I survey conducted eight years previously that had a response rate of $92 \%{ }^{50}$; (c) the key analyses (for example, type of infection, antibiotic use) entailed comparisons within the childhood infections groups and/or within the general population group and we obtained similar odds ratio estimates in each group. Thus, the low response rates may have biased the findings for childhood infections (which entailed comparing the general population and childhood infection groups), but any bias is likely to be weak, and they are unlikely to have biased the findings for medication use.

A second limitation of the data is that the childhood infection group survey was national, whereas the general population survey was in the Wellington region. Once again, this may have biased the findings for childhood infections, but could not have biased the findings for medication use as they involved analyses that were internal to each group. Furthermore, the bias in the findings for infections is likely to be small because in the previous ISAAC phase I survey, the asthma prevalence in Wellington children was found to be very close to that in the overall ISAAC data for New Zealand (a prevalence of $25.1 \%$ in Wellington and $24.5 \%$ nationally for current wheezing ${ }^{50}$ ). A related issue is that the childhood infections group survey was restricted to children who had not moved since their original notification to the EpiSurv database. This could introduce a bias, but this would occur only if the prevalence of asthma was considerably different in children who had moved than in children who had not.

A third limitation of the data is that information on environmental exposures (other than notifiable childhood infections) was obtained retrospectively. Thus, there are different issues involved in assessing the validity of the findings for infections, and those for other exposures; since the latter could be subject to recall bias. However, this would only occur if the recall of particular exposures (for example, paracetamol use early in life) was different in parents of children with asthma than in parents of children without asthma. Parents of children from the childhood infections group might also recall better medication use early in life than parents of children in the general population group; however, this would not explain the reported findings because the observed associations of paracetamol and antibiotic use early in life with subsequent childhood asthma were similar within the childhood infections group and within the general population group.

Currently the role of infections in the aetiology of asthma is not clear; results of several studies suggest that exposure to a broad range of infectious agents (including respiratory infections) may protect against atopy and atopic disease such as allergic asthma and hay fever. ${ }^{6-11} 18$ 26-28 However, other studies have shown that some, for example, respiratory viral infections (in particular RSV), are associated with an increased risk of wheeze. ${ }^{16}{ }^{51} \mathrm{We}$ found only a weak protective effect of childhood infections that appeared to be confined to children who had not used antibiotics in the first year of life. This is puzzling to some extent because it is perhaps more likely that these children experienced viral infections that are considered risk factors for asthma. Thus, the reason for this comparatively modest protective effect may be because the EpiSurv database included a wide range of infections, potentially including infections that are positively associated with asthma symptoms. In fact, we found little difference when we studied the site and type of infection independently, but these still represent rather broad categories and although they have all been termed "serious" they actually include a wider spectrum. At one end, they are largely self limiting diseases such as campylobacteriosis with a very low casefatality rate. At the other is meningococcal disease, which causes serious invasive disease in the form of septicaemia and/or meningitis, almost invariable results in hospitalisation (the hospitalisation rate for campylobacteriosis is about $7 \%$, compared with about $97 \%$ for meningococcal disease, which carries a case-fatality rate in New Zealand of $4.5 \%{ }^{52}$ ). Presumably the immune response to these infections is similarly different in its form and intensity that may have different and potentially opposite effects on the $\mathrm{TH}_{1} / \mathrm{TH}_{2}$ balance and the development of atopy and asthma. A further differentiation was unfortunately not possible because of the low numbers for specific infectious diseases.

While we found at most a weak protective effect of childhood infections, we found an approximately twofold increased risk of asthma, and to a lesser extent hay fever and eczema, at age 6-7 years in children whose parents reported that they had used antibiotics in the first year of life. Our findings are generally consistent with other evidence that antibiotic use in the first year of life increases the subsequent risk of asthma, ${ }^{28-36}$ although a number of authors have commented on the possibility that these associations may be attributable to reverse causation in that frequent upper respiratory infections, often and early symptom of asthma, are usually treated with antibiotics. ${ }^{31}{ }^{36}$ The association was stronger for asthma and hay fever than for eczema, and it was observed both within the general population group, and within the childhood infections group.

We also found an association of paracetamol use in the first year of life, and also recent paracetamol use, with asthma at age 6-7 years. The latter finding is consistent with previous studies. ${ }^{37-40}$ One possibility is simply that health professionals encourage their asthmatic patients to take paracetamol rather than aspirin because the latter may worsen asthma severity, but Shaheen $e t a^{37}$ argued that this was unlikely to explain their findings. Possible underlying mechanisms involve increased oxidative stress due to the ability of paracetamol to reduce levels of the anti-oxidant glutathione in immune cells, thus depleting anti-oxidant defences and promoting $\mathrm{TH}_{2}$ allergic inflammation ${ }^{37}$ as well as increased viral loads as a side-effect of paracetamol use, possibly leading to asthma..$^{53}$ Thus, there is some preliminary evidence linking paracetamol use to current asthma in both children and adults but, to our knowledge, this is the first report associating paracetamol use early in life with subsequent asthma risk in children. As with adults, the possibility cannot be excluded that the association is due to reverse causation. Furthermore, it may not necessarily involve the same mechanisms as the association of more recent paracetamol use with asthma.

In summary, the findings reported here are consistent with other evidence that the use of antibiotics and/or paracetamol early in life may increase the risk of asthma. They are also consistent with preliminary evidence associating recent paracetamol use with an increased risk of asthma. Any protective effect of notifiable childhood infections was weak

\section{ACKNOWLEDGEMENTS}

Institute of Environmental Sciences and Research (ESR) staff assisted with extracting data from the National Notifiable Disease Database (EpiSurv).

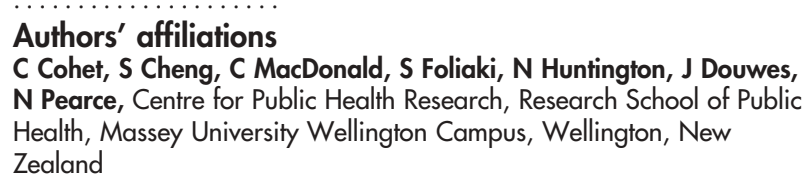

Authors' affiliations

C Cohet, S Cheng, C MacDonald, S Foliaki, N Huntington, J Douwes, Health, Massey University Wellington Campus, Wellington, New Zealand 
M Baker, Institute of Environmental Science amd Research, Kenepuru Science Centre, Porirua, Wellington, New Zealand

Funding: the Centre for Public Health Research is supported by a Program Grant, and this study was funded by a Project Grant, from the Health Research Council of New Zealand.

Conflicts of interest: none declared.

\section{REFERENCES}

1 Pearce N, Douwes J, Beasley R. Asthma. In: Detels RMJ, Beaglehole R, Tanaka H, eds. Oxford textbook of public health. 4th ed. Vol 3. Oxford: Oxford University Press, 2002:1255-77.

2 Douwes J, Pearce N. Asthma and the westernization 'package'. Int J Epidemiol 2002;31:1098-102.

3 Pearce N, Douwes J, Beasley R. The rise and rise of asthma: a new paradigm for the new millennium? J Epidemiol Biostat 2000;5:5-16.

4 Holt PG, Sly PD, Bjorksten B. Atopic versus infectious diseases in childhood: a question of balance? Pediatr Allergy Immunol 1997;8:53-8.

5 Martinez FD, Holt PG. Role of microbial burden in aetiology of allergy and asthma. Lancet 1999:354(suppl 2):SII1 2-15.

6 Martinez FD, Stern DA, Wright AL, et al. Association of non-wheezing lower respiratory tract illnesses in early life with persistently diminished serum IgE levels. Group Health Medical Associates. Thorax 1995;50:1067-72.

7 Strachan DP. Family size, infection and atopy: the first decade of the "hygiene hypothesis". Thorax 2000;55(suppl 1):S2-10.

8 Matricardi PM, Rosmini F, Ferrigno L, et al. Cross sectional retrospective study of prevalence of atopy among Italian military students with antibodies against hepatitis A virus. BMJ 1997;314:999-1003.

9 Aaby $\mathrm{P}$, Shaheen $\mathrm{SO}$, Heyes $\mathrm{CB}$, et al. Early $\mathrm{BCG}$ vaccination and reduction in atopy in Guinea-Bissau. Clin Exp Allergy 2000;30:644-50.

10 Shaheen SO, Aaby P, Hall AJ, et al. Measles and atopy in Guinea-Bissau. Lancet 1996;347:1792-6.

11 Shirakawa T, Enomoto T, Shimazu S, et al. The inverse association between tuberculin responses and atopic disorder. Science 1997:275:77-9.

12 Matricardi PM, Rosmini F, Riondino S, et al. Exposure to foodborne and orofecal microbes versus airborne viruses in relation to atopy and allergic asthma: epidemiological study. BMJ 2000;320:412-17.

13 Gruber C, Kulig M, Bergmann R, et al. Delayed hypersensitivity to tuberculin, total immunoglobulin $\mathrm{E}$, specific sensitization, and atopic manifestation in longitudinally followed early Bacille Calmette-Guerin-vaccinated and nonvaccinated children. Pediatrics 2001;107:E36.

14 Alm JS, Lilja G, Pershagen G, et al. Early BCG vaccination and development of atopy. Lancet 1997:350:400-3.

15 Alm JS, Swartz J, Lilia G, et al. Atopy in children of families with an anthroposophic lifestyle. Lancet 1999;353:1485-8.

16 Nafstad P, Magnus P, Jaakkola JJ. Early respiratory infections and childhood asthma. Pediatrics 2000;106:E38.

17 Sigurs N, Biarnason R, Sigurbergsson F, et al. Respiratory syncytial virus bronchiolitis in infancy is an important risk factor for asthma and allergy at age 7. Am J Respir Crit Care Med 2000;161:1501-7.

18 Flynn MG. Respiratory symptoms, bronchial responsiveness, and atopy in Fijian and Indian children. Am J Respir Crit Care Med 1994:150:415-20.

19 Matricardi PM, Rosmini F, Panetta V, et al. Hay fever and asthma in relation to markers of infection in the United States. J Allergy Clin Immunol 2002;110:381-7.

20 Ball TM, Castro-Rodriguez JA, Griffith KA, et al. Siblings, day-care attendance, and the risk of asthma and wheezing during childhood. N Engl J Med 2000;343:538-43.

21 Celedon JC, Wright RJ, Litonjua AA, et al. Day care attendance in early life, maternal history of asthma, and asthma at the age of 6 years. Am J Respir Crit Care Med 2003;167:1239-43.

22 Celedon JC, Litonjua AA, Ryan L, et al. Day care attendance, respiratory tract illnesses, wheezing, asthma, and total serum IgE level in early childhood. Arch Pediatr Adolesc Med 2002;156:241-5.

23 Cooper PJ. Can intestinal helminth infections (geohelminths) affect the development and expression of asthma and allergic disease? Clin Exp Immunol 2002:128:398-404.

24 Cooper PJ, Chico ME, Bland $M$, et al. Allergic symptoms, atopy, and geohelminth infections in a rural area of Ecuador. Am J Respir Crit Care Med 2003;168:313-17.

25 Palmer $\mathrm{L}$, Celedon JC, Weiss ST, et al. Ascaris lumbricoides infection is associated with increased risk of childhood asthma and atopy in rural China. Am J Respir Crit Care Med 2002;165: 1489-93.
26 Scrivener S, Yemaneberhan $\mathrm{H}$, Zebenigus $\mathrm{M}$, et al. Independent effects of intestinal parasite infection and domestic allergen exposure on risk of wheeze in Ethiopia: a nested case-control study. Lancet 2001;358:1493-9.

27 Illi S, von Mutius E, Lau S, et al. Early childhood infectious diseases and the development of asthma up to school age: a birth cohort study. BMJ $2001 ; 322: 390-5$

28 Mendall MA, Kumar D. Antibiotic use, childhood affluence and irritable bowel syndrome (IBS). Eur J Gastroenterol Hepatol 1998;10:59-62.

29 Faroogi IS, Hopkin JM. Early childhood infection and atopic disorder. Thorax 1998;53:927-32.

30 Wickens K, Pearce N, Crane J, et al. Antibiotic use in early childhood and the development of asthma. Clin Exp Allergy 1999;29:766-71.

31 Droste $\mathrm{JH}$, Wieringa $\mathrm{MH}$, Weyler JJ, et al. Does the use of antibiotics in early childhood increase the risk of asthma and allergic disease? Clin Exp Allergy 2000;30:1547-53.

32 McKeever TM, Lewis SA, Smith C, et al. The importance of prenatal exposures on the development of allergic disease: a birth cohort study using the West Midlands general practice database. Am J Respir Crit Care Med 2002;166:827-32.

33 McKeever TM, Lewis SA, Smith C, et al. Early exposure to infections and antibiotics and the incidence of allergic disease: a birth cohort study with the West Midlands general practice research database. J Allergy Clin Immunol 2002;109:43-50

34 Xu B, Pekkanen J, Jarvelin MR, et al. Maternal infections in pregnancy and the development of asthma among offspring. Int J Epidemiol 1999;28:723-7.

35 Celedon JC, Litonjua AA, Ryan L, et al. Lack of association between antibiotic use in the first year of life and asthma, allergic rhinitis, or eczema at age 5 years. Am J Respir Crit Care Med 2002;166:72-5.

36 Wjst $M$, Hoelscher $B$, Frye $C$, et al. Early antibiotic treatment and later asthma. Eur J Med Res 2001;6:263-71.

37 Shaheen SO, Sterne JA, Songhurst CE, et al. Frequent paracetamol use and asthma in adults. Thorax 2000;55:266-70.

38 Shaheen SO, Newson RB, Sherriff A, et al. Paracetamol use in pregnancy and wheezing in early childhood. Thorax 2002;57:958-63.

39 Lesko SM, Louik C, Vezina RM, et al. Asthma morbidity after the short-term use of ibuprofen in children. Paediatrics 2002;109:1-4.

40 Newson RB, Shaheen SO, Chinn S, et al. Paracetamol sales and atopic disease in children and adults: an ecological analysis. Eur Respir $J$ 2000;16:817-23.

41 Asher MI, Keil U, Anderson HR, et al. International Study of Asthma and Allergies in Childhood (ISAAC): rationale and methods. Eur Respir J 1995;8:483-91.

42 Baker M, Roberts A. A new schedule of notifiable diseases for New Zealand. New Zealand Public Health Reports 1996;5:33-37.

43 ISAAC Steering Committee. Worldwide variation in prevalence of symptoms of asthma, allergic rhinoconjunctivitis, and atopic eczema: ISAAC. Lancet 1998:351:1225-32.

44 The International Study of Asthma and Allergies in Childhood (ISAAC) Steering Committee. Worldwide variations in the prevalence of asthma symptoms: the International Study of Asthma and Allergies in Childhood (ISAAC). Eur Respir J 1998;12:315-35.

45 Strachan D, Sibbald B, Weiland S, et al. Worldwide variations in prevalence of symptoms of allergic rhinoconjunctivitis in children: the International Study of Asthma and Allergies in Childhood (ISAAC). Pediatr Allergy Immunol 1997;8:161-76.

46 Williams H, Robertson C, Stewart A, et al. Worldwide variations in the prevalence of symptoms of atopic eczema in the International Study of Asthma and Allergies in Childhood. J Allergy Clin Immunol 1999;103:125-38.

47 Pearce N, Beasley R, Burgess C, et al. Asthma epidemiology: principles and methods. New York: Oxford University Press, 1998.

48 Mantel N, Haenszel W. Statistical aspects of the analysis of data from retrospective studies of disease. J Natl Cancer Inst 1959;22:719-48.

49 Breslow N, Day N, eds. Statistical methods in cancer research. Vol I. The analysis of case-control studies. IARC Scientific Publications. Vol 32. Lyon: IARC, 1980.

50 Asher MI, Barry D, Clayton T, et al. The burden of symptoms of asthma, allergic rhinoconjunctivities and atopic eczema in children and adolescents in six New Zealand centres: ISAAC Phase One. N Z Med J 2001;114:114-20.

51 Martinez FD. Respiratory syncytial virus bronchiolitis and the pathogenesis of childhood asthma. Pediatr Infect Dis J 2003;22(suppl 2):S76-82.

52 Baker MG, Martin DR, Kieft CE, et al. A 10-year serogroup B meningococcal disease epidemic in New Zealand: descriptive epidemiology, 1991-2000. J Paediatr Child Health 2001:37:S13-19.

53 Balzer B. Paracetamol and asthma. Thorax 2000;55:882 